\title{
Geografia do litoral Em praias e várzeas de Gustavo Barroso
}

\author{
Coastal geography \\ In praias e várzeas by Gustavo Barroso
}

\section{Geografia costera \\ Em praias e várzeas de Gustavo Barroso}

\author{
iD) (9) Tiago Vieira Cavalcante \\ Universidade Federal do Ceará - Fortaleza - Ceará - Brasil \\ tiagocavalcante@ufc.br \\ iD Eustógio Wanderley Correia Dantas \\ Universidade Federal do Ceará - Fortaleza - Ceará - Brasil \\ ewcdantas@gmail.com
}

Resumo: Neste ensaio abordamos alguns temas caros ao conhecimento geográfico a partir da obra Praias e Várzeas do escritor cearense Gustavo Barroso (1888-1959). Entendendo que a obra literária não deve ser pensada como mero documento, mas como expressão da passagem do homem pela Terra, nosso objetivo é o de perscrutarmos temas passíveis de serem relacionados à noção de geografia do litoral, como paisagem, lugar, geograficidade, imaginação, urbanização e modernização, todos eles capazes de elucidar, em diferentes escalas, a diversidade das dinâmicas litorâneas, do passado e do presente. Geografia e literatura, portanto, são conhecimentos que universalizam experiências singulares e nos ajudam a compreender a condição humana no mundo.

Palavras-chave: Geografia Humanista; Geografia Literária; Literatura Cearense.

Abstract : In this essay we approached some themes estimated to the
geographic knowledge from the work Praias e Várzeas by Gustavo Barroso 
(1888-1959), writer from Ceará. Understanding that the literary work should not be thought of as a mere document, but as an expression of the passage of man on Earth, our objective is to investigate themes that can be related to the notion of coastal geography, such as landscape, place, geographicity, imagination, urbanization and modernization, all of them capable of elucidating, at different scales, the past and the present of diversity of coastal dynamics. Geography and literature, therefore, are knowledge that universalize singular experiences and help us to understand the human condition in the world.

Keywords: Humanist Geography; Literary Geography; Ceará Literature.

Resumen: En este ensayo abordamos algunos temas apreciados por el conocimiento geográfico de la obra Praias e Várzeas del escritor de Ceará Gustavo Barroso (1888-1959). Entendiendo que la obra literaria no debe considerarse como un mero documento, sino como una expresión del paso del hombre en la Tierra, nuestro objetivo es investigar temas que puedan estar relacionados con la noción de geografía costera, como paisaje, lugar, geograficidad, imaginación, urbanización y modernización, todas ellas capaces de aclarar, a diferentes escalas, la diversidad de la dinámica costera, pasada y presente. La geografía y la literatura, por lo tanto, son conocimientos que universalizan experiencias singulares y nos ayudan a comprender la condición humana en el mundo.

Palabras clave: Geografía Humanista; Geografía Literaria; Literatura do Ceará. 


\title{
O homem e o mar: paisagem e lugar
}

\author{
A aurora se desamarra do cais. \\ Um barco singra o peito \\ rosado do mar. \\ A manhã sacode as ondas \\ e os coqueiros. \\ O azul estica a linha do horizonte. \\ Na praia, um pescador arrasta \\ um sol de algas. \\ Em suas mãos, um peixe salta: \\ ó palavra escamosa, \\ espírito agitado das águas. \\ (ESPÍNOLA, 2001, p. 14).
}

No poema do poeta cearense Adriano Espínola, intitulado Pesca, entre coqueiros, barcos, ondas e peixes, a relação entre o homem e o mar é expressa pela paisagem que envolve o pescador. Paisagem onde estão dispostos os elementos de sua história e de sua geografia, ampliada pelo azul do céu que abrange continente e oceano, estabilidade e movimento, apresentando um horizonte de possibilidade e esperança.

Essa dualidade tão premente que parece perseguir a vida dos homens, podemos ler no conto Velas Brancas, do livro Praias e Várzeas, de Gustavo Barroso, em que conhecemos a história de Matias Jurema, velho pescador do Meireles em Fortaleza - CE. No conto, a partir do pescador que já não tinha nem a mesma visão nem as mesmas forças para navegar mar adentro, sabemos mais das vivências de quem está situado entre dois mundos:

Somente o mar o atraía e a terra ele desprezava por sua ingratidão. Ah! ela era miserável e covarde. A sua vingança estava na impassibilidade. Não tinha cóleras a sua inércia. O mar, não. Esse, quando tinha raiva, encapelava-se furioso e 
jogava os grandes navios sobre os rochedos e despedaçava as jangadas no abraço de uma onda. [...] A terra, essa estendiase plana, calada e concentrada. Levava anos para dar um fruto, meses para produzir uma fécula. Tinha-se de esburacá-la com pás e enxadas, para se arrancar alguma cousa. Parece que dava esmolas. O seio largo do mar estava aberto a todo mundo. Era inesgotável. Todos os seus tesouros lá estavam para quem tivesse ânimo de ir buscá-los (BARROSO, 1979, p. 7).

Entre o homem e o mar, a praia. Na praia, ponte de areia entre o aqui e o alhures, o pescador compreende os ventos e as marés e avalia se "o mar está para peixe", como ensina o velho ditado. Também ali, arria o produto de seu trabalho, de dias de labuta por entre as águas, motivo de sua sobrevivência. A praia, para quem faz da pesca o seu ofício, é paisagem e lugar.

A praia é paisagem, porque, ao mesmo tempo, natureza e cultura. A natureza da praia abrange dunas, falésias, mangues, restingas e o limite do mar a ser desvendado. A cultura da praia carrega um cotidiano, uma sociabilidade, uma lida e uma herança. Natureza e cultura no entendimento da paisagem são, portanto, a expressão concreta da relação do homem com o meio.

O pescador percebe o mar, o conhece e o anseia com respeito. Para ele o horizonte não é só o que a vista alcança, mas um conjunto de sentimentos, receios e sentidos. Voltemos a Matias Jurema, pescador que tem a vista consumida pela catarata. Matias, por tal motivo, apreendia a paisagem pelos ouvidos, “[...] já que não podia mais deleitar-se com os olhos. Imaginava a paisagem tão sua conhecida em outros tempos e quedava silencioso, o cachimbo esquecido ao canto da boca" (BARROSO, 1979, p. 5). É sobre essa paisagem marítima que o pescador se detém enquanto ser-no-mundo, lançando daí seus sonhos e suas aventuras. Relação mais íntima entre a natureza e o homem, em que o pescador e a paisagem são um só (DARDEL, 2011; ANDREOTTI, 2013).

A praia é lugar, pois é recorte da Terra como base e destino do homem. Base, em termos geomorfológicos, de grãos de quartzo, 
Geografia do litoral Em praias e várzeas de Gustavo Barroso

Tiago Vieira Cavalcante. Eustógio Wanderley Correia Dantas

depósito de areias acumuladas provenientes dos rios e/ou das marés (GUERRA, 1993). Destino constituído enquanto geografia em ato, pois da praia parte o pescador, condição que faz dele mais sujeito marítimo que continental. É o que provava a vida do velho Matias: "Dedicara a vida somente ao oceano. A terra só lhe trouxera desgraças" (BARROSO, 1979, p. 8).

Não obstante a praia é lugar privilegiado de diálogo (DARDEL, 2011) e, por conseguinte, de afetos, pois na praia o pescador estabelece sua morada, o seu lar, esclarecendo o quanto o sentido de lugar para a geografia é revelador das experiências humanas que se dão no cotidiano, como explica Tuan (2012). Desse modo, o lugar faz o elo (MAFFESOLI, 2004) entre a morada do pescador, seu mundo imediato, e os outros tantos mundos possíveis. É isso que podemos ler em trecho do conto de título $O$ Pescador, em que paisagem e lugar se confundem na descrição vívida, poética, da ambiência do pescador-personagem Pedro Jojó, capaz de nos transportar a uma singular geografia do litoral:

Madrugava. Nascia a lua. O mar clareava aos poucos. Na crista arrugada das ondas vagarosas a luz joeirava cisalhas de prata. A praia clara recurvava-se entre duas finas e avançadas pontas, arenosa, sem rochas, onde as vagas adormeciam, gemendo, num grande espreguiçamento branco. Para o poente, vultos e coqueirais, batidos do vento, destacavam-se negros no céu estrelado. Nas dunas desertas e tristes apontoavam a brancura da areia mirradas moitas de pinhão bravo; de quando a quando coleavam salsas rasteiras como serpentes enormes. Ao norte, uma das pontas de terra que longamente enfiava pelo oceano terminava em rochedos escuros, aqui dispersos, ali quase igualmente intervalados à guisa de gigânteas alpondras: e por sobre eles, flava, fulgurante, bocejava a intercadências a lanterna benéfica dum farol.

Ao fundo de pequena chanfradura, entre morros e mangues, o Pacoti rosnava, derramando o seu tributo de águas doces da terra nas salsas águas do oceano. Todos os rumores dos 
matos, das águas e dos bichos notívagos diluíam-se na noite enluarada. Um eflúvio dormente desprendia-se dos cajueirais floridos e fecundados, errava na face da terra uma canseira, um quê de sutil que impelia à madorra, ao sono e à preguiça. Tudo foi clareando mais e mais. Depois a lua resplandeceu alta e uma refulgência prateada, com uns raros tons de azinhavre, derramou-se por sobre as cousas (BARROSO, 1979, p. 19).

A descrição literária anima as feições da Terra com as vibrações coloridas do instante. Escrita, de acordo com Dardel (2011, p. 4), que “[...] tornando-se mais literária, perde clareza, mas ganha em intensidade expressiva, devido ao estremecimento da existência que é dada pela dimensão temporal restaurada".

Concordando com Marandola Jr. (2014), que é pela paisagem que chegamos ao lugar, ou com Cresswell (2015), que entende o lugar como o espaço vivido desvelado pela qualidade de vida característica em uma paisagem, compreende-se que a paisagem e o lugar são uma composição, aquela anunciando este, situando o cotidiano do pescador, sujeito que tem sua geografia definida na relação entre a terra e o mar.

Na Figura 1, temos a paisagem e o lugar na praia do Meireles nos anos de 1930 em Fortaleza - CE. Uma geografia vernacular do litoral, com casas de pescadores, jangadas, dunas à mostra e extensos coqueirais em cotidiano diálogo com o mar. Destaque para a jovem vestida com trajes de banho, prenúncio das mudanças materiais e simbólicas que ocorrem nessa e em outras tantas praias no decorrer do século 20. 
Geografia do litoral Em praias e várzeas de Gustavo Barroso

Tiago Vieira Cavalcante. Eustógio Wanderley Correia Dantas

Figura 1: Paisagem e lugar na praia do Meireles nos anos de 1930 em Fortaleza - CE.

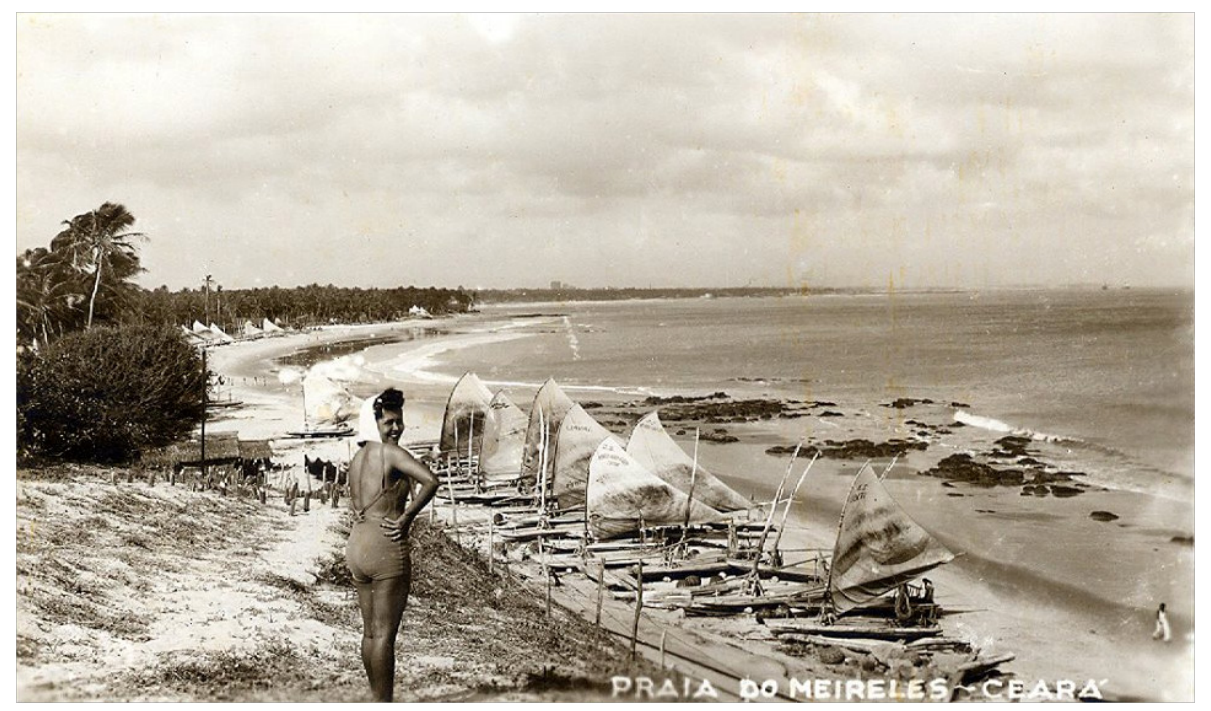

Fonte: Arquivo Nirez.

Iniciamos o nosso texto com alguns trechos de contos contidos no livro Praias e Várzeas, de Gustavo Barroso, para logo posicionarmos o leitor diante da potência da literatura em desvelar e/ ou enriquecer a geografia. A literatura, nesse sentido, não deve ser pensada como mero documento, mas como uma expressão da passagem do homem pelo mundo, da mesma forma que a geografia, embora com distintos propósitos e fins.

Importante destacar que essa potência da literatura é vigorada pela geografia humanista, nos idos dos anos de 1970, pelo interesse desta abordagem na realidade que se abre diante das vivências cotidianas atravessadas por sentimentos e imaginações (BROSSEAU, 2007). Tais características humanas revelam as relações que os sujeitos mantêm com tudo aquilo que os circunda, pois o homem é ser-no-mundo cuja presença está intrinsecamente ligada à paisagem e ao lugar onde ele assenta sentido à sua existência (LÉVY, 1981; HOYAUX, 2009).

A geografia humanista promove desse modo uma geografia literária, isto é, uma associação entre a geografia e a literatura que, guardando as suas especificidades, busca compreender as 
diferentes maneiras do homem (d)escrever o mundo, tornando-o inteligível, mesmo que para isso esse mundo precise ser (re)criado (CAVALCANTE, 2019).

Diante do exposto, nosso objetivo neste ensaio é o de perscrutarmos temas caros ao conhecimento geográfico a partir da obra Praias e Várzeas de Gustavo Barroso. Temas passíveis de serem relacionados à noção de geografia do litoral, como paisagem e lugar, antes apresentados, além de geograficidade, imaginação, urbanização e modernização, que permeiam as seções seguintes; todos eles capazes de elucidar diferentes escalas das dinâmicas litorâneas, do passado e do presente.

\section{O escritor e a obra: geograficidade e imaginação}

O escritor cearense Gustavo Barroso nasceu no dia 29 de dezembro de 1888 numa casa da Rua Formosa, hoje Barão do Rio Branco, em Fortaleza - CE. Considerado um polígrafo, por ter escrito romances, contos, crônicas, ensaios, além de livros sobre a nossa história e o nosso folclore, foi muito apegado ao seu povo e a sua terra e por isso de "[...] uma sensibilidade e uma inteligência de sentido telúrico indiscutível" (COLARES, 1979, p. X). Para Campos (1988, p. 21), em Gustavo Barroso, “O Ceará, a começar de Fortaleza, estaria tão entranhado nele, e, de tal forma, que acabaria sendo o despertar de sua inegável grandeza literária". Esse telurismo, essa geografia entranhada, reflete uma relação próxima do escritor com as principais paragens características do Ceará: o sertão e o litoral.

Vale aqui novamente evocarmos Dardel (2011) para tratarmos da geograficidade, capaz de compor uma geografia do homem interessado no mundo circundante. Para o referido geógrafo, a geograficidade é a descoberta do homem como um ser fundamentalmente telúrico, consciente da inserção do elemento terrestre entre as dimensões fundamentais da sua existência. 
Geografia do litoral Em praias e várzeas de Gustavo Barroso

Tiago Vieira Cavalcante. Eustógio Wanderley Correia Dantas

Sabendo disso, podemos nos perguntar: não seriam os escritores sujeitos sensíveis a uma geograficidade que lhes é própria? E, por tal motivo, capazes de (re)escrever o mundo a partir de vivências e lembranças pessoais? Não seriam essas vivências e lembranças pessoais os subsídios essenciais para a imaginação criadora do escritor?

Segundo o geógrafo Bertrand Lévy (1992), não existem escritos sem fundamento geográfico, expressos no envolvimento entre o escritor e a natureza que dá sentido à sua existência. Para Manoel de Barros (2015, p. 102), "O olho vê, a lembrança revê e, a imaginação transvê", e com sua poesia o poeta pantaneiro nos ensina que diante da realidade, da geografia que o envolve, o escritor sempre traça novas linhas para as paisagens, os lugares e as pessoas que conhece, (re)inventando o mundo que se abre diante dele.

Evidentemente o propósito do escritor não é o de pensar-fazer geografia. Apesar de sabermos que a geografia é um saber ao alcance de todos, fazendo-nos detentores de geografias pessoais (LOWENTHAL, 1985; CLAVAL, 2010), o escritor, diferente do geógrafo profissional, geralmente não intenciona fazer do espaço a sua personagem principal. Se o espaço aparece, é porque invariavelmente, assim como o tempo, ele nos atravessa e nos é inextricável, sendo mapa indispensável das tramas da vida e também literárias, por isso meio de expressão da condição humana (MONTEIRO, 2002).

O sertão e o litoral, portanto, são os espaços vividos de Gustavo Barroso. O sertão parecia tomar conta de suas principais lembranças, como destaca Campos (1988, p. 39), “O seu grande mar de aventura acabaria sendo o sertão. Por ele iria navegar como ninguém". É do sertão que retira os elementos indispensáveis para a escritura de seu consagrado livro de estreia, Terra de Sol, publicado em 1912. Mas o litoral também não deixaria de ser para ele uma de suas opções de fuga e inspiração. Com Praias e Várzeas, seu segundo livro, publicado em 1915, o escritor, que quando menino sonhava em ser marinheiro, se reconcilia com o mar. 
Geografia do litoral Em praias e várzeas de Gustavo Barroso

Tiago Vieira Cavalcante. Eustógio Wanderley Correia Dantas

Cabe dizer que na obra em questão nem todos os contos, onze no total, têm situadas as suas narrativas no espaço litorâneo. São nos quatro primeiros, Velas Brancas; Finados; Naufrágio e O Pescador, que lemos histórias sobre a saga dos pescadores no âmbito de geografias de paisagens tipicamente litorâneas. As várzeas, terrenos baixos e mais ou menos planos que se encontram junto ao leito maior dos rios (GUERRA, 1993), e os seus arredores, compõem o espaço imaginado pelo escritor no restante dos contos - Santa; Espectro; A Luíza do Seleiro; O Patuá; Absalão; O Filho do Guarari; Emboscada - e por isso mesmo não nos detemos a estes.

$\mathrm{Na}$ obra estão suas vivências de criança, quando aprendera com pescadores e jangadeiros os segredos, histórias e astúcias do mar. Logo, o cotidiano na praia não the guardava segredos (CAMPOS, 1988). Certamente por isso a possibilidade de lermos no conto Finados, tão detalhado apresto do pescador em direção ao oceano:

\begin{abstract}
Chegou à praia, preparou o "paquete", abriu a vela triangular, empurrou-o sobre os dois rolos até as espumas; fê-lo boiar; depois voltou e trouxe os rolos para fora do alcance da maré cheia. Foi empurrando a jangadinha de encontro às vagas. A uma certa distância da costa, quando a água Ihe passava da cintura, saltou nela, sentou-se no banco do governo, empunhou o leme largo, metendo-o no macho, retesou a escota, enrolando-a nos espeques, pôs a cuia de atirar água na vela ao alcance da mãe. Fez-se ao largo (BARROSO, 1979, p. 13).
\end{abstract}

Essa particular geograficidade ligada ao litoral, possível de ser observada na Figura 2, em que o homem, o mar e a jangada são uma paisagem só, fomenta a imaginação do escritor de Praias $e$ Várzeas. Imaginação relacionada ao imaginário ou à multiplicidade de imagens elaboradas desde tempos remotos sobre os mares e oceanos, numa visão ocidental. 
Geografia do litoral Em praias e várzeas de Gustavo Barroso

Tiago Vieira Cavalcante. Eustógio Wanderley Correia Dantas

Figura 2: Jangada na Praia do Mucuripe em Fortaleza - CE, em foto de 1962.

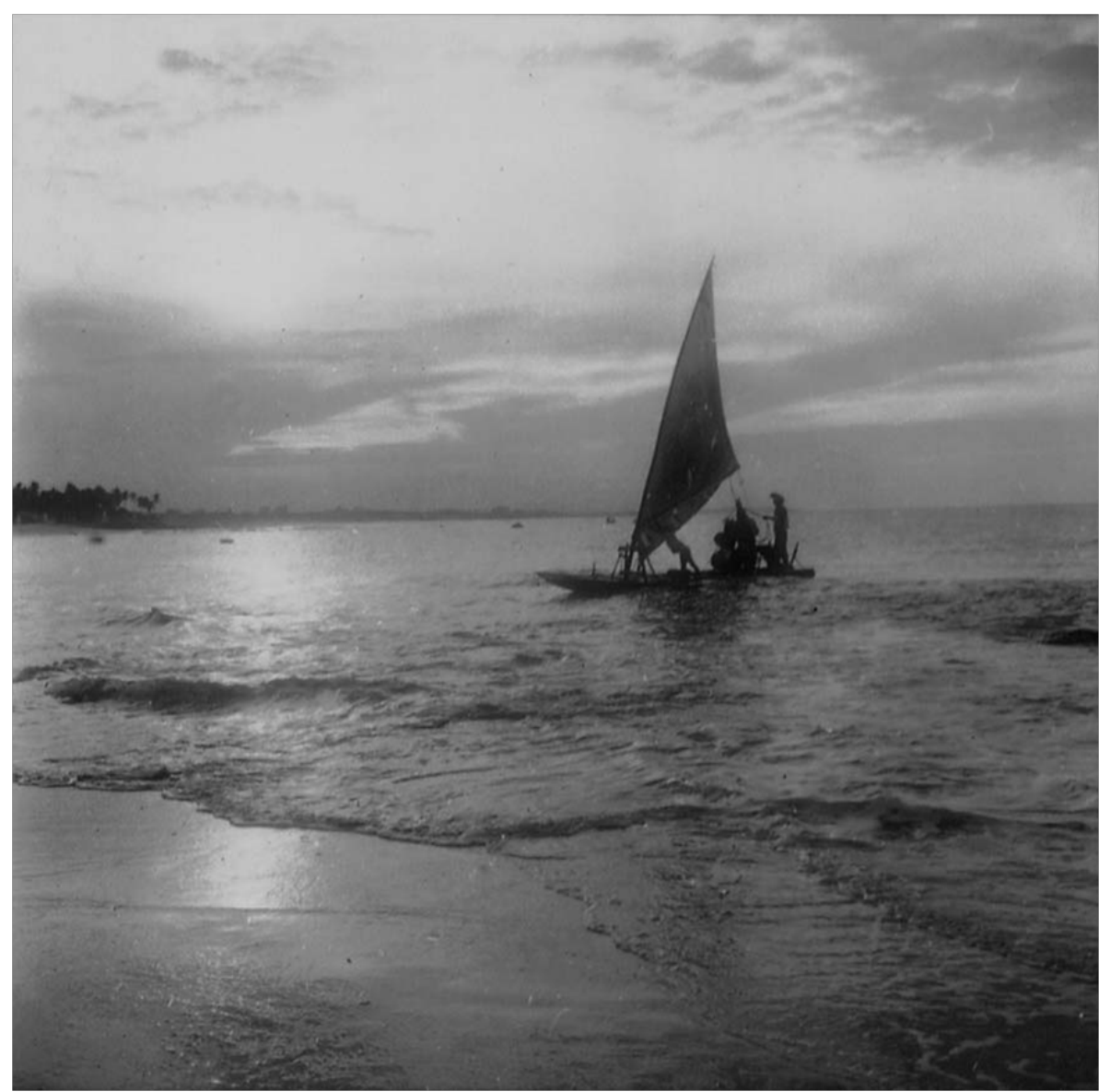

Fonte: Instituto Brasileiro de Geografia e Estatística - IBGE.

Yi-Fu Tuan (2013), fazendo uma leitura da Bíblia, nos conta da cosmogonia referente à criação do homem, indicando o quanto Deus claramente favoreceu a terra, onde situou o Jardim do Éden, em detrimento da imprecisão bárbara dos mares. O referido geógrafo ainda escreve sobre como os cartógrafos, desde o tempo dos gregos até o período das grandes navegações, subestimavam o tamanho dos oceanos a serem cruzados, além de inserirem monstros e bestas nas bordas dos mapas do mundo até então conhecido.

Na Idade Média, o oceano era impróprio para a vida terrestre, pois nele residiam criaturas infernais e era a morada do próprio diabo. Visão religiosa, católica em especial, que marcou a rejeição do 
Geografia do litoral Em praias e várzeas de Gustavo Barroso

Tiago Vieira Cavalcante. Eustógio Wanderley Correia Dantas

homem pelo mar. O oceano, nesse âmbito, era uma arma de Deus, por isso se enfurecia diante dos pecados humanos. Temia-se mesmo a presença dos pescadores, por pensarem que estes traziam as mazelas do oceano para o continente (MATOS e VASCONCELOS, 2010). O que lemos no conto de título Naufrágio, mais um do livro Praias e Várzeas, reforça bem esse humor oceânico, por vezes desatinado e repentino, fazendo perecer embarcações e homens de toda sorte:

E o iate virava de bordo no espumejar da vaga.

O vento foi rondando no quadrante de nordeste. Soprou depois do norte. O São Rafael pôs-se a capa. O vento mudou ainda: veio de sueste e então insistente, forte, terrível, a crescer, a crescer numa espantosa velocidade. O iate não podia mais alcançar a terra. Voou, afastando-se da costa entrevista numa fagueira esperança, corrido pela rajada. O mar picava-se. Vinham borbulhas soluçar na superfície. la-se fazendo escuro. Não se avistava uma jangada, um farol, uma rocha. A costa apagarase de todo. Agora era só céu, céu e mar que rugia de encontro a cachopos, distantes e ocultos traiçoeiramente sob o manto revolto do oceano (BARROSO, 1979, p. 17).

Notadamente esse imaginário não impede que o homem no decorrer do tempo se relacione das mais variadas formas com o mar, mesmo tendo sido essa relação, por um lado, temerosa e cuidadosa, por outro, aventureira e curiosa, afinal, para o bem ou para o mal, os mares sempre exerceram grande fascinação. Dardel (2011, p. 79) trata disso ao nos contar sobre a geografia das velas desfraldadas, início do regime mercantilista, em que é inaugurado novo capítulo da geografia econômica mundial e outro momento da relação entre o homem e o mar. Para ele, as preocupações políticas e mercantis, por si só, não explicam a vontade intrépida de o homem correr o mundo. Aliado a essa vontade existe o que ele denominou de "poética do descobrimento geográfico", que funda, com a "criação" de espaço e de uma abertura para o mundo de 
Geografia do litoral Em praias e várzeas de Gustavo Barroso

Tiago Vieira Cavalcante. Eustógio Wanderley Correia Dantas

uma extensão do homem, uma nova relação entre o homem e a Terra.

A partir do renascimento, o avanço das técnicas de navegação e o uso de instrumentos como a bússola, o quadrante, o astrolábio, etc., assim como o conhecimento mais detalhado das características da natureza a ser desbravada e explorada, apontavam para o papel técnico-científico na construção de uma terra plenamente cógnita, como é possível ler na extraordinária história de John Harrison, relojoeiro inglês, que com a invenção de um relógio marítimo de alta precisão, hoje denominado cronômetro, resolve para os navegadores o problema da longitude no século 18. A partir disto quem navegasse em alto mar não mais se perderia (SOBEL, 1997).

É certo que mesmo diante de um planeta totalmente mapeado, os mitos, lendas e crenças relativas ao cotidiano daqueles que vivem com os olhos e os sonhos voltados para o horizonte marítimo não são abandonados, como fica claro novamente no conto Finados, no qual lemos a preocupação de alguns pescadores com a vida do colega Lucas que teimava em pescar em pleno dia santo:

- Onde vai Lucas?

- Onde vou? Vou pescar!

O tom da voz é de quem estranhava que se admirassem de seu proceder, e de quem, selvagem e rude, não gostava de conselhos.

- Pescar hoje! dia santo! dia de finados! exclamou o velho, esbugalhando os olhos ante aquela ação, que no seu sincero fanatismo religioso achava ser uma monstruosidade, um pecado mortal, um verdadeiro atentado contra as leis divinas que regulam o trabalho do homem. E os outros velhos, deixando as poitas e tarrafas, levantando-se, e os que vinham da latada, já em círculo, cheios de espanto:

- Pescar hoje! dia de finados! (BARROSO, 1979, p. 12). 
Os trechos dos contos esclarecem que mesmo diante de uma história teimosamente contada de forma linear, os mitos e ritos, as crenças e crendices, apesar das mudanças técnicas, científicas e informacionais, perduram enriquecendo nossas geografias pessoais. A própria literatura é importante fomentadora dessas subjetividades componentes do nosso imaginário sobre as mais diversas paisagens e lugares.

Diegues (1998), por exemplo, em discussão sobre a maritimidade e a insularidade na literatura europeia e brasileira, demonstra como esta tem a capacidade de guardar e expressar numerosos mitos e lendas relativos ao mar e às ilhas, mesmo seus significados se transformando segundo os tempos e as sociedades. E sobre a literatura nacional, indica a existência de poucos escritores terem tratado da marinharia, trazendo, entre outros, exemplos conhecidos como Jorge Amado, com Mar Morto e José Lins do Rêgo, em Água-Mãe.

Notoriamente, Gustavo Barroso deve entrar no grupo de escritores que bem ilustram em suas letras o mar, as praias, os pescadores e toda a ambiência característica da zona litorânea, a cearense particularmente. Não somente por Praias e Várzeas, aqui em questão, mas também por Mississipi, romance publicado em 1961, postumamente.

Para Dantas (2011), a tomada de consciência gradual do mar e do marítimo no domínio da literatura é basilar para novas atitudes, por parte da sociedade cearense e, particularmente, fortalezense, diante do elemento líquido. Há com isso, aos poucos, uma valorização das praias por parte da população, principalmente de uma elite de origem interiorana que, no caso de Fortaleza, constituiu uma cidade com alma de sertão.

Em verdade, mundo a fora, a relação do homem com o mar vai ganhando outros contornos e significados e no Ceará isto não é exceção, pois, inserido em uma dinâmica cada vez mais global e modernizante, o estado passa a instaurar novas práticas em re- 
Geografia do litoral Em praias e várzeas de Gustavo Barroso

Tiago Vieira Cavalcante. Eustógio Wanderley Correia Dantas

lação ao litoral. Dinâmica praieira que muda ao sabor das ondas culturais, políticas e econômicas da sociedade.

\section{O pescador e a terra: urbanização e modernização}

Mencionamos que a publicação de Praias e Várzeas foi em 1915. Provavelmente por tal data, e pelo aspecto topofílico (TUAN, 2012) que caracteriza a escrita de Gustavo Barroso, nos é apresentada na obra uma geografia do litoral tão bucólica. Essa geografia que parece perdurar no Ceará até o início do século 20, tem na praia a frequentação majoritária de marinheiros, estivadores e pescadores. Os primeiros vinculados à dinâmica dos portos, do comércio, da relação geopolítica anunciada desde as grandes navegações. Os últimos, ocupantes há muito tempo do litoral, estabelecem com - sedentarismo as primeiras comunidades de pescadores (DANTAS, 2011).

Até o início do século 20 as aglomerações urbanas concentradas ao longo da costa brasileira tinham em comum o uso das faixas de praia para as atividades portuárias e pesqueiras, além do despejo de lixo (MATOS e VASCONCELOS, 2010). Essa lida urbana concebia cidades pensadas de costas para o mar, portanto com suas construções voltadas para os sertões. No caso de Fortaleza, importantes projetos urbanos tracejados no século 19, como os de Silva Paulet (1824) e de Adolf Herbster (1875), revelam uma cidade distanciada da praia, porque pensada para e pelas culturas mais abastadas (DANTAS, 2011).

Os projetos citados são exemplos da busca pela modernização de uma cidade que aos poucos ganha importância geoestratégica diante da rede urbana cearense. Cabe à Fortaleza a materialização de suas conquistas, na concepção de prédios, no traçado de ruas e avenidas, na chegada de novidades técnicas como a eletricidade etc., mas também no estabelecimento de um modo de vida urbano concatenado com os mais recentes acontecimentos do mundo, 
afinal urbanização e modernização são processos que andam de mãos dadas.

Esse modo de vida diz respeito à maneira como as pessoas pensam, constroem e habitam o espaço, política, econômica e culturalmente. No âmbito do litoral, isso está relacionado ao que o historiador Alain Corbin (1989) denomina de invenção da praia, isto é, um ajustamento do espaço litorâneo em prol da conformação de novas dinâmicas infraestruturais e sociais. Enquanto na Europa esse ajustamento atravessa os séculos 18 e 19, no Brasil é somente no despertar do século 20 que a sociedade vislumbra a zona litorânea como área de lazer e residência, primeiro no Rio de Janeiro, posteriormente difundindo-se por todo o país (FERREIRA E SILVA, 2001; MATOS e VASCONCELOS, 2010).

Não que práticas diversas no litoral não ocorressem. Além das relacionadas ao porto e à pesca, também aconteciam banhos de mar, serenatas, caminhadas pela orla, tratamentos terapêuticos etc. Todavia, estas não promovem processo intensivo de urbanização das zonas de praia (DANTAS, 2011).

A Figura 3 retrata bem a multiplicidade de dinâmicas ocorridas na orla marítima fortalezense, mais especificamente na Praia de Iracema do final dos anos de 1930. Na foto temos a pesca, o porto e os lazeres, como o passeio na faixa de praia e o banho de mar, compondo uma mesma paisagem. 
Geografia do litoral Em praias e várzeas de Gustavo Barroso

Tiago Vieira Cavalcante. Eustógio Wanderley Correia Dantas

Figura 3: Dinâmicas praieiras: a pesca, o porto e o lazer na praia em Fortaleza de 1939.

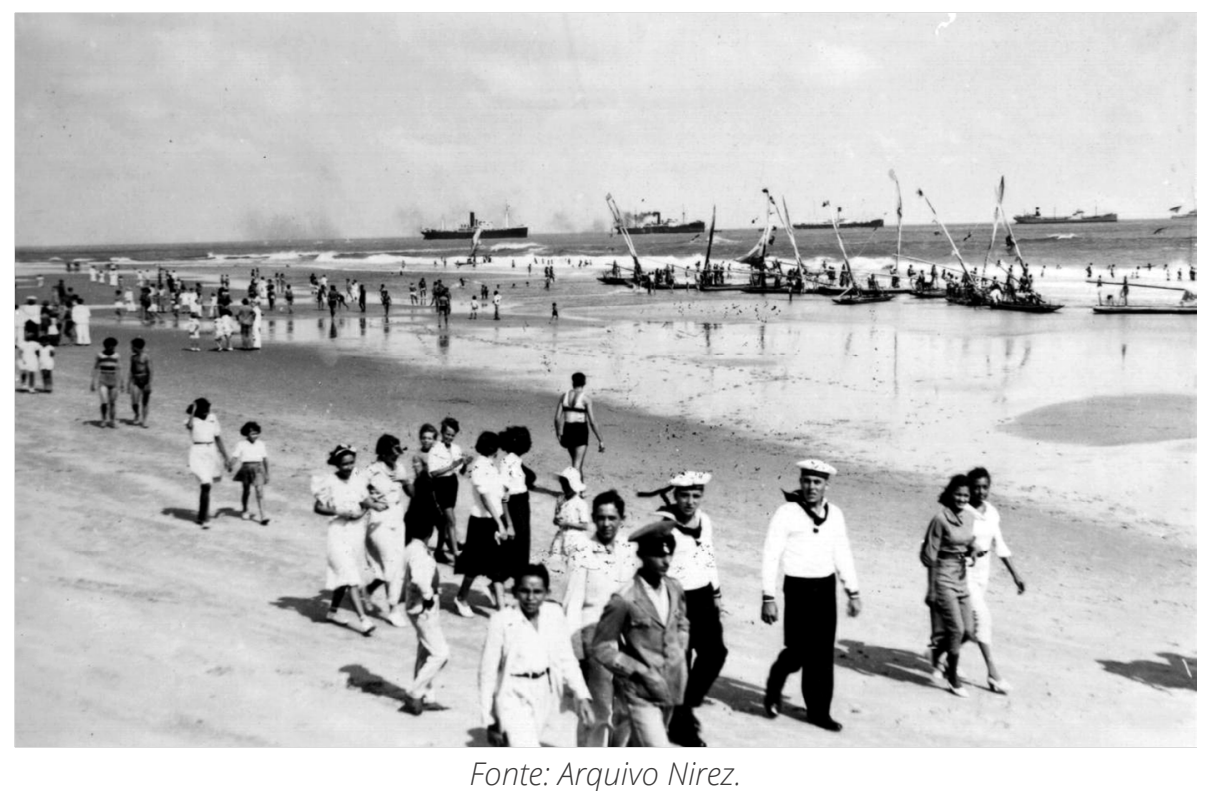

Em trecho do conto Finados, lemos sobre algumas atividades cotidianas, de encontro e de lazer, dos povos do mar, daqueles que pareciam viver em um espaço-tempo lento, praticamente idílico, exemplar de uma geografia do litoral d'outrora:

Numa volta da costa, mais adiante, onde as ondas remansavam de encontro a um espigão de areia orlado de arrecifes, depois de o lavarem por cima, banhavam-se meninos em gritaria, a jogar cambapé e brincar galinha-cheia.

- Galinha-cheia!

- Cheia!

Era um alto, esguio, avermelhado ao sol, com penugens de oiro pelo corpo em fora, que berrava, uma pedra na mão:

- Galinha-cheia!

E o coro, dez ou doze, um muito alvo, quase todos cor de cobre sujo, um muito preto, retinto, respondia:

- Cheia!

A pedra era atirada nágua, bem longe. Todos mergulhavam; iam buscá-la ao fundo de areia limpa. E o que voltava com ela na 
mão tornava triunfalmente:

- Galinha-cheia!

Quase à orla do mar, junto a um bote adernado, uns velhos teciam tarrafas, sentados; outros desenrolavam poitas de escotas e de tauaçus, "corregendo" as falhas. Eram trabalhos leves, para divertir (BARROSO, 1979, p. 11).

É no elo com a Europa, a partir das práticas sucedidas neste continente em relação ao seu litoral, que a elite brasileira, e mais especificamente a cearense, passa a incorporar as zonas de praia como espaço de lazer e veraneio (DANTAS, 2011). É desse modo que a urbanização vai à praia na constituição das cidades modernas (PEREIRA, 2014). Arquitetura do mar, responsável pela (re) definição de construções e significados na orla marítima (CORBIN, 1989).

No caso de Fortaleza, a passagem de uma cidade litorânea interiorana para uma cidade litorânea marítima - com ligações ainda fortes com o interior -, significa a ocupação da zona de praia como lugar de habitação, veraneio e lazer, como podemos ver na Figura 4, constituindo disso um importante imobiliário urbano. Imobiliário, de início, relacionado ao crescimento da cidade pelos ganhos econômicos do algodão, posteriormente, com incentivos de programas vinculados ao turismo, fomentando a urbanização litorânea não somente na metrópole, mas em todo o litoral cearense e mesmo nordestino, respeitando as particularidades de cada uma dessas escalas (DANTAS, 2011). 
Geografia do litoral Em praias e várzeas de Gustavo Barroso

Tiago Vieira Cavalcante. Eustógio Wanderley Correia Dantas

Figura 4: Praia do Futuro nos anos de 1960 em Fortaleza - CE.

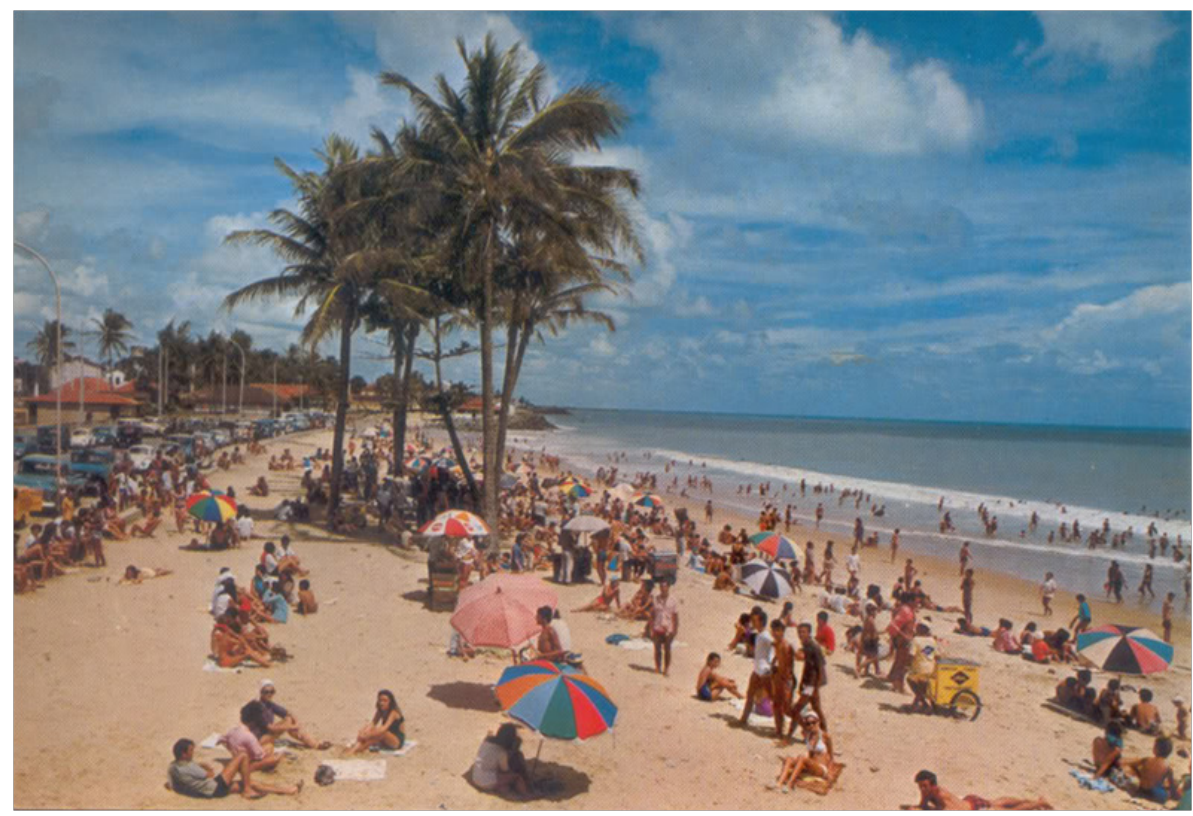

Fonte: Arquivo Nirez.

No que diz respeito ao turismo, por parte do Estado compete a construção de estradas, de redes elétricas e de comunicação, de esgotamento sanitário, de calçadões e mesmo de imagem a ser publicizada no exterior, assim como o fomento ao investimento da iniciativa privada na infraestruturação hoteleira, alimentícia e de lazer (Figura 5). Nesse mesmo contexto, a inclusão e prática de esportes como o surfe, o kitesurf, o windsurf, o mergulho, o vôlei, o futebol de areia, enfim uma multiplicidade de práticas que redefinem espacialidades (a maneira como são organizados os objetos espaciais em sua lógica e processo de formação) e geograficidades (os laços de cumplicidade que os homens em sua individualidade e/ou coletividade estabelecem com o ambiente) na zona costeira (MARANDOLA JR. e OLIVEIRA, 2009; PEREIRA e DANTAS, 2019). 
Geografia do litoral Em praias e várzeas de Gustavo Barroso

Tiago Vieira Cavalcante. Eustógio Wanderley Correia Dantas

Figura 5: A cidade se volta para o mar: Fortaleza e seu imobiliário urbano litorâneo.

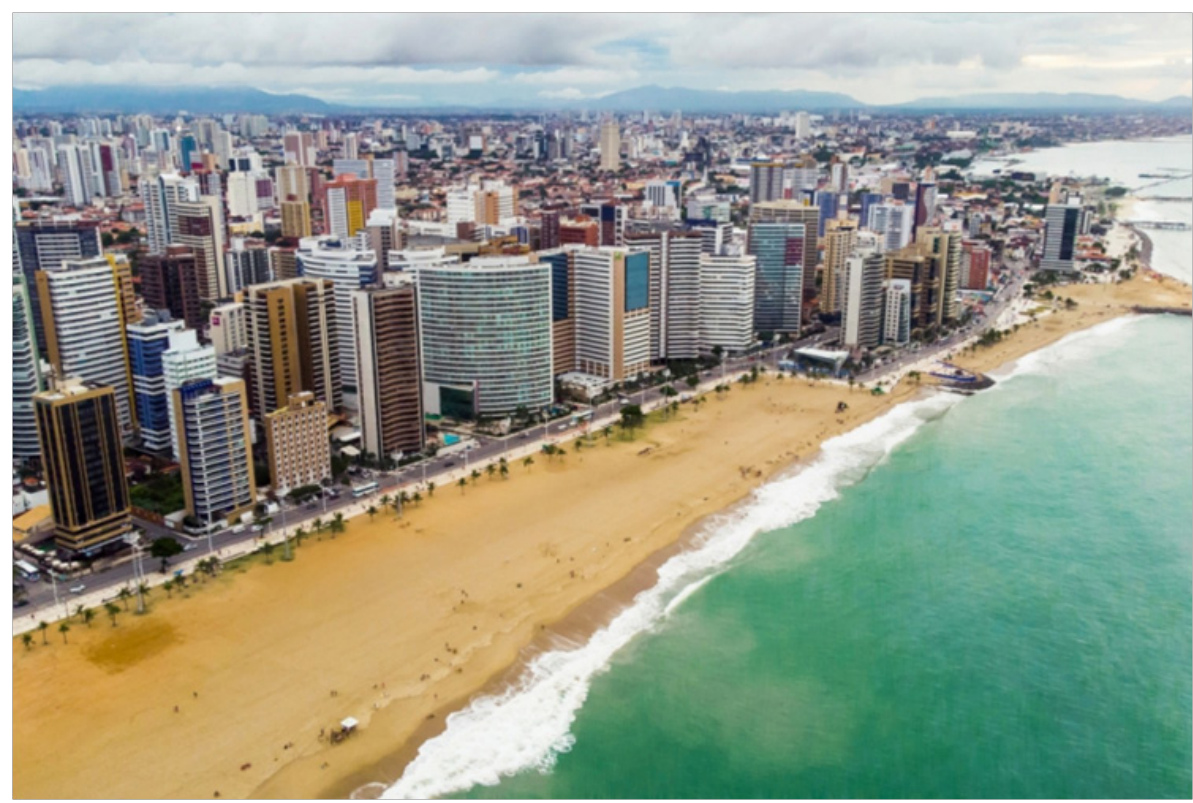

Fonte: http://opovo.com.br. Foto de Francisco Fontenele.

O panorama exposto não se pretende completo e os autores citados oferecem trabalho aprofundado sobre o tema da urbanização e modernização litorânea. Destarte, dois são os motivos para apresentarmos tal panorama.

Primeiro, para contextualizarmos a obra Praias e Várzeas, esclarecendo os aspectos que a caracterizam, representativos de um espaço-tempo peculiar, hoje difícil de ser observado devido às mudanças substanciais que tivemos na nossa geografia litorânea. Segundo, porque essas mudanças provocam uma reviravolta na discussão das socialidades humanas presentes na orla marítima e a literatura, nesse caso, nos serve de mote para ampliarmos o nosso olhar geográfico sobre esse espaço em particular.

Exemplo disso é a condição conflitante em que se encontra o pescador, sujeito que sempre teve o mar como horizonte e destino e agora precisa se preocupar com a terra, com a luta pela terra. Dantas (2005, p. 272), explica: “[...] o pescador, que antes se batia contra o mar e seus elementos para garantir sua sobrevivência, tem que bater-se em terra para garantir sua permanência 
Geografia do litoral Em praias e várzeas de Gustavo Barroso

Tiago Vieira Cavalcante. Eustógio Wanderley Correia Dantas

nas praias". Conflito desigual que culmina na sua expulsão para as grandes cidades ou para áreas menos valorizadas próximas de sua antiga moradia. A tendência é que o pescador abandone as atividades tradicionais, sendo obrigado a inserir-se, muitas vezes, no âmbito do informal, transformando, em consequência dessas perdas, o seu modo de vida.

O resultado é que atualmente esses pescadores, organizados em comunidades pesqueiras por todo o litoral, necessitam resistir no mar, em disputa constante com empresários da pesca predatória, mas também na terra, em oposição à especulação imobiliária, à grilagem e, de forma mais geral, à degradação ambiental provocada em espaço hoje de grande interesse socioeconômico. Com isso, com a luta pela terra, como sugere Dantas (2005), o pescador redescobre o mar, dele juntando forças para continuar a (r)existir por uma geografia do litoral diversa, plural.

Diante do discutido, é possível assegurar que a literatura, assim como a geografia, nos faz pensar nos movimentos da sociedade, nos seus fluxos, nas mudanças que se dão no espaço no decorrer do tempo, portanto em diferentes períodos de contexto particular. Geografia e literatura são assim conhecimentos que universalizam experiências singulares e com isso nos ajudam a compreender o mundo, relacionando passado e presente na construção de trilhas para o futuro.

\section{Geografia e literatura: caminhos e encontros}

O trajeto que fizemos nesse texto demonstra a riqueza da obra literária em fazer repercutir uma variedade de discussões geográficas. Temas como paisagem, lugar, geograficidade, imaginação, urbanização e modernização são (re)apresentados levando-se em consideração as (con)vivências do escritor, como também os mapas e as tramas presentes na obra. Podemos dizer que para nós 
a obra literária, sobretudo, abre a discussão e não meramente a ilustra.

Locais apontados em Praias e Várzeas por Gustavo Barroso, como, por exemplo, o Meireles e o Mucuripe, hoje bairros litorâneos da cidade de Fortaleza, o Rio Pacoti, que em sua foz faz a divisa dos municípios de Fortaleza e Aquiraz, e os municípios de Trairí (com a citada praia de Mundaú) e Aracatí, entre outras tantas localidades, há muito tiveram as suas paisagens modificadas, compondo hoje outra cartografia, e mesmo outra cartografia literária. São lugares de novas dinâmicas e, por conseguinte, de novos sentidos.

O mesmo pode-se dizer da geograficidade e da imaginação que caracteriza essas paisagens e lugares. Devido ao processo crescente de urbanização e de modernização do espaço que por meio das redes alcança todas as coordenadas, as (i)materialiades características dos modos de vida também são transformadas. Isso faz da geografia e da literatura conhecimentos que nos ajudam a apreender as conformações do espaço no tempo.

Não poderíamos deixar de instigar o leitor a pensar as geografias dos litorais pelos mais distintos ângulos, explorando outros escritores e obras, do Brasil e do exterior, afinal a leitura que realizamos é uma entre tantas possíveis e qualquer obra enseja muitas interpretações, como nos ensina Carlos Fuentes (2007) ao afirmar que a obra literária é escrita finita que provoca leituras infinitas.

\title{
Referências
}

\author{
ANDREOTTI, Giuliana. Paisagens culturais. Curitiba: Editora \\ UFPR, 2013.
}

BARROS, Manoel de. Meu quintal é maior do que o mundo. (Antologia). Rio de Janeiro: Objetiva, 2015. 
BARROSO, Gustavo. Praias e várzeas; Alma sertaneja. Rio de Janeiro: José Olympio, 1979.

BROSSEAU, Marc. Geografia e literatura. In: CORRÊA, Roberto L.; ROSENDAHL, Zeny (org.). Literatura, música e espaço. Rio de Janeiro: EdUERJ, 2007. p. 17-77.

CAMPOS, Eduardo. Gustavo Barroso: sol, mar e sertão. Fortaleza: EUFC, 1988.

CAVALCANTE, Tiago V. Geografia literária em Rachel de Queiroz. Fortaleza: Edições UFC, 2019.

CLAVAL, Paul. Terra dos homens: a geografia. São Paulo: Contexto, 2010.

COLARES, Otacílio. Introdução crítica: Gustavo Barroso e o Regionalismo. In: BARROSO, Gustavo. Praias e várzeas; Alma sertaneja. Rio de Janeiro: José Olympio, 1979. p. ix-xx.

CORBIN, Alain: Território do vazio: a praia e o imaginário ocidental. São Paulo: Companhia das Letras, 1989.

CRESSWELL, Tim. Place: an introduction. $2^{\mathrm{a} e d}$. London: Wiley Blackwell, 2015.

DANTAS, Eustógio W. C. O pescador na terra. In: SILVA, José B. da; CAVACANTI, Tércia C.; DANTAS, Eustógio W. C. (Orgs.). Ceará: um novo olhar geográfico. Fortaleza: Editora Demócrito Rocha, 2005, p. 263-279.

DANTAS, Eustógio W. C. Mar à vista: estudo da maritimidade em Fortaleza. 2ªed. Fortaleza: Edições UFC, 2011.

DARDEL, Eric. O homem e a Terra: natureza da realidade geográfica. São Paulo: Perspectiva, 2011.

DIEGUES, Antonio C. Ilhas e mares: simbolismo e imaginário. São Paulo: HUCITEC, 1998.

ESPÍNOLA, Adriano. Beira-Sol. $4^{\mathrm{a} e d}$. Rio de Janeiro: Topbooks, 2001. 
FERREIRA E SILVA, Mauro Gil. A praia e o imaginário social: discurso médico e mudança de significados na cidade do Rio de Janeiro. In: ROSENDAHL, Zeny; CORRÊA, Roberto L. (org.). Paisagem, imaginário e espaço. Rio de Janeiro: EdUERJ, 2001. p. 183-206.

FUENTES, Carlos. Geografia do romance. Rio de Janeiro: Rocco, 2007.

\section{GUERRA, Antônio T. Dicionário Geológico-Geomorfológico.}

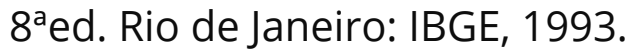

HOYAUX, André-Frédéric. Phénoménologie et géographie. HAL: archives ouvertes, p. 1-3, 2009. Disponível em: https:// halshs.archives-ouvertes.fr/halshs 00380150/file/Hoyaux_ Phenomenologie_geographie.pdf. Acesso em: 22 jan. 2020.

LÉVY, Bertrand. "Humanistic Geography" ou le pari humaniste de la géographie anglo-saxonne. L'Espace Géographique, tome 10, n. 4, p. 301- 304, 1981.

LÉVY, Bertrand. Hermann Hesse: une géographie existentielle. Jose Corti, 1992.

LOWENTHAL, David. Geografia, experiência e imaginação: em direção a uma epistemologia geográfica. In: CHRISTOFOLETTI, Antônio (org.). Perspectivas da geografia. $2^{a} e d$. São Paulo: DIFEL, p. 103-141, 1985.

MAFFESOLI, Michel. Notas sobre a pós-modernidade: o lugar faz o elo. Rio de Janeiro: Atlântica Editora: 2004.

MARANDOLA JR., Eduardo. Viagens por paisagens: experiências do sentir e do querer. In: ALVES, Ida et al (org.). Estudos de paisagem: literatura, viagens e turismo cultural. 2014. p. 53-63.

MARANDOLA JR., Eduardo; OLIVEIRA, Lívia de. Geograficidade e espacialidade na literatura. Geografia, Rio Claro, v. 34, n. 3, p. 487-508, set./dez. 2009.

MATOS, Fábio de O.; VASCONCELOS, Fábio P. Içar velas: algumas considerações sobre as venturas na relação entre o homem e o 
mar. ACTA Geográfica, Boa Vista, v. 4, n. 7, p. 67-78, jan./jul. de 2010.

MENESES, Eduardo D. B. de. Gustavo Barroso: um cearense "Ariano". Fortaleza: Museu do Ceará, Secretaria da Cultura do Estado do Ceará, 2006.

MONTEIRO, Carlos A. de F. O mapa e a trama: ensaios sobre o conteúdo geográfico em criações romanescas. Florianópolis: Editora da UFSC, 2002.

PEREIRA, Alexandre Q. A urbanização vai à praia: vilegiatura marítima e metrópole no Nordeste do Brasil. Fortaleza: Edições UFC, 2014.

PEREIRA, Alexandre Q.; DANTAS, Eustógio W. C. Dos banhos de mar aos esportes nas zonas de praia e no mar. Sociedade \& Natureza, Uberlândia, MG, v.31, p. 01-24, 2019.

SOBEL, Dava. Longitude: a verdadeira história de um gênio solitário que resolveu o maior problema científico do século XVIII. $2^{\mathrm{a} e d .}$ Rio de Janeiro: Ediouro, 1997.

TUAN, Yi-Fu. Topofilia: um estudo da percepção, atitudes e valores do meio ambiente. Londrina: Eduel, 2012.

TUAN, Yi-Fu. Romantic geography: in search of the sublime landscape. Madison: The University of Wisconsin Press, 2013.

WRIGHT, John K. Terrae incognitae: o lugar da imaginação na Geografia. Geograficidade, Niterói, v. 4, n. 2, p. 4-18, Inverno 2014.

Todos os autores ofereceram substanciais contribuições científicas e intelectuais ao estudo. As tarefas de concepção e design do estudo, preparação e redação do manuscrito, bem como, revisão crítica foram desenvolvidas em grupo. O primeiro autor, Tiago V. Cavalcante, ficou especialmente responsável pelo desenvolvimen- 
to teórico-conceitual e dos argumentos. O segundo autor Eustógio W. C. Dantas, também ficou responsável pelo desenvolvimento teórico-conceitual, além dos procedimentos técnicos e revisão dos conteúdos e análises.

Tiago Vieira Cavalcante - Graduado e Mestre em Geografia pela Universidade Federal do Ceará. Doutor em Geografia pela Universidade Estadual Paulista Júlio de Mesquita Filho. Atualmente éProfessor Adjunto no Departamento de Geografia da Universidade Federal do Ceará. Orcid: https://orcid.org/0000-0002-9668-996X

Eustógio Wanderley Correia Dantas - Possui graduação pela Universidade Estadual do Ceará. Mestrado em Geografia pela Universidade de São Paulo e Doutorado em Geographie et Amenagement pela Université Paris-Sorbonne. Atualmente é Professor Titular da Universidade Federal do Ceará. Orcid: https://orcid.org/0000-0001-9656-1328

Recebido para a publicação em 21 de maio de 2020 Aceito para a publicação em 4 de julho de 2020 Publicado em 18 de agosto de 2020 